\title{
Taper Training in Sport
}

\section{Sporda "Taper" Antrenmanları}

\author{
Halit Egesoy \\ Sport Sciences Faculty, Pamukkale University, Denizli, Turkey
}

H. Egesoy

0000-0003-1347-8647

Geliş Tarihi/Date Received: 22.10.2018

Kabul Tarihi/Date Accepted: 28.04.2019

Yayın Tarihi/Published Online: 05.09.2019

\section{Yazışma Adresi /}

Corresponding Author:

Halit Egesoy

Pamukkale Üniversitesi, Spor

Bilimleri Fakültesi, Denizli,

Turkey

E-mail: hegesoy1@hotmail.com

(C2020 Türkiye Spor Hekimleri Derneği. Tüm hakları saklıdır.

\section{ABSTRACT}

The aim of this study is to investigate the effects of taper training on the performances of athletes by examining the studies conducted on taper training. Qualitative research methods were used to interpret the studies on taper applications published between 1981-2018. Document analysis was used as data collection method and the obtained data were analysed by content analysis method.

1-4 weeks duration in taper is the most suitable period for optimal performance in sport. Taper has an effect of 7-14 days. When this period continues for another 14 days, significant performance improvement is achieved. As the training load is reduced during the taper, fatigue decreases, recovery occurs in shorter time and the performance of the athlete is improved. During the taper period training volume is reduced, the intensity is maintained or slightly reduced. By reducing the intensity, volume and/or frequency of training, a reduction in the load of the training occurs, as well. Careful planning of the reduction in the training volume minimizes the detraining effect. Following the taper training; blood volume, number of red blood cells, blood lactate, maximal heart rate, level of some hormone and enzyme levels, running economy and muscle glycogen stores of the athletes are increased.

In conclusion; taper training contributes to improvement in athletic performance.

Keywords: Taper training, blood lactate, heart rate

Öz

Bu çalışmanın amacı "taper" antrenmanlarla ilgili yapılmış çalıșmaları inceleyerek bu antrenmanların sporcuların performansları üzerindeki etkisini araştırmaktır. 1981-2018 yılları arasında yayınlanan "taper" uygulamaları alanındaki çalışmaların derinlemesine incelenmesi ve yorumlanması için nitel araştırma yöntemleri kullanılmıştır. Veri toplama yöntemi olarak doküman analizi kullanılmış, elde edilen veriler içerik analizi yöntemiyle analiz edilmiştir.

"Taper" uygulamalarında 1-4 haftalık sürenin optimal performans için en uygun olduğu rapor edilmiştir. Bu uygulamalar 7-14 gün arasında etkisini göstermekte, 14 gün daha devam ettiğinde sporcularda önemli performans gelişimi elde edilmektedir. "Taper" döneminde sporcuya uygulanan antrenman yükü azaldığı için yorgunluk azalmakta, toparlanma daha kısa sürede gerçekleşmekte ve sporcunun performansında gelişme olmaktadır. Antrenman hacmi bu dönemde düşürülmekte, antrenmanın şiddeti korunmakta ya da hafif bir artış olmaktadır. Antrenmanın yoğunluğu, hacmi ve/veya sıkığının azaltılmasıyla antrenmanın yükünde bir azaltma yapılmaktadır. Bunu yaparken sporcuda "detraining" etkisi göstermemesi için dikkatli olmak gerekir. "Taper" döneminde antrenman hacminde yapılan azaltmaların doğru planlanmasıyla "detraining" etkisi görülmeyecektir. "Taper" sonrası, sporcuların kan hacmi, kırmızı kan hücresi, kan laktat, maksimal kalp atım hızı, bazı hormon ve enzim düzeyleri, koşu ekonomisi ve kas glikojen depolarında bazı artışlar olduğu belirlenmiştir.

Sonuç olarak, "taper" antrenmanları sportif performansa katkıda bulunmaktadır.

Anahtar Sözcükler: "Taper" antrenmanı, kan laktatı, kalp atım hızı 
Available at: http://journalofsportsmedicine.org and http://dx.doi.org/10.5152/tjsm.2020.162

Cite this article as: Egesoy H. Taper training in sport. Turk J Sports Med. 2020;55(1):69-78.

\section{GİRIŞ}

Elit düzeydeki sporcularla çalışan antrenörler için temel hedef, sporcuların önemli yarışmalarda maksimum performanslarını ortaya koyabilmeleri için sistematik ve kontrollü bir antrenman programı sunmaktır. Böyle bir program içinde "taper" uygulamalarına da yer verilmesi oldukça önemlidir (1-3). Elit sporlarda "taper" stratejilerinin uygulanması büyük ölçüde antrenörlerin kendi gözlemleri ve deneyimlerine bağlı olarak, sporcularla günlük etkileşim ile belirlenmektedir (4).

"Taper" sporcularda yeterli toparlamanın gerçekleşmesini sağlamak için antrenman hacmindeki ve/veya şiddetindeki azalmalarla karakterize edilmektedir (5). Önemli yarışmalar öncesinde, sporcuların performanslarında gelişim sağlamak amacıyla antrenman yükü, yoğunluk, hacim veya sıklığında yapılan azaltmaya "taper" adı verilmektedir (6-8). Diğer bir tanıma göre, "taper" yüksek yoğunlukta yapılan bir antrenmandan sonra organizma üzerinde oluşan stresten kurtulmak için yarıșmalardan önce kullanılan bir toparlanma tekniğidir (9). Bir başka tanıma göre "taper" antrenmanı, yarışma öncesi, maksimal yarışma performansı sağlayabilmek amacıyla çeşitli antrenman periyotları içinde fiziksel ve fizyolojik toparlanmanın sağlanabilmesi için antrenman yükünün azaltılmasıdır (10-15). "Taper" hedef yarışmadan önceki son birkaç hafta içinde uygulanan antrenman programındaki son adım olarak da ifade edilmekte$\operatorname{dir}(8,15)$.

Costil ve ark. tarafından yapılan çalışmada, yüzücülerin yarıştan en az 2 hafta önce "taper" uygulandığında en iyi performanslarını sergiledikleri gözlenmiştir (16). Bu çalışma ilk olarak Carlile tarafından ortaya atılan hedef yarıştan önce uzun "taper" düşüncesinin önemini desteklemektedir (17). 30 yll öncesine kadar sezonun en önemli yarışlarından önce antrenmanların yoğunlaşması konusunda yaygın bir kanı bulunuyordu. Antrenörler böylece sporcuların optimal performansa ulaşacaklarını düşünmekte ve "ta- per" uygulamalarının sporcuların performansları üzerinde olumsuz etkileri olacağına inanmaktaydılar (18). Sporcuların yarışma öncesi optimal performans için yoğun ve şiddetli antrenmanlar yapmaları, yarışmalara yorgun çıkmalarına ve performanslarının bozulmalarına neden olmakta ve beklenen başarı elde edilememekteydi $(19,20)$. Günümüzde hedef yarıştan önce uygulanacak "taper" süresinin ne kadar olması gerektiği konusunda kesin bir bilgi bulunmamaktadır. Noakes "taper" süresinin en az 10-14 gün olması, vücudun tam dinlenmesi için yoğun antrenman ve yarış aylarından sonra daha da uzun tutulması gerektiğini belirtmiştir (17).

"Taper" uygulamasının verimliliği, "taper" dönemi öncesi yapılan antrenman yüküne, "taper" süresi ve tipine, antrenman yükünde yapılan düşüşün oranına ve antrenman hacmi ile şiddeti arasındaki dengeye bağlı olarak değişmektedir (21,22).

\section{"Taper" Antrenmanlarının Amacı}

"Taper" antrenmanlarının amacl, sporcularda birikmiş fizyolojik ve psikolojik yorgunluğun etkilerini azaltmak, toparlanma sürecini hızlandırmak ve performans gelişimlerine katkıda bulunmaktır $(10,11,23)$.

"Taper" antrenmanlarının diğer amaçları da şöyle belirtilmektedir:

- Vücut fonksiyonlarının normale dönmesini sağlamak.

- Homeostatik dengenin normale dönmesine katkıda bulunmak.

- Enerji depolarının yenilenme sürecini hızlandırmak.

- Enzimatik fonksiyonların yeniden normal hale gelmesini sağlamak $(10,11)$. 


\section{"Taper" Antrenman Tipleri}

Yapılan farklı çalışmalarda, "taper" antrenmanları çeşitli şekillerde kategorize edilmektedir.

\section{Step “Taper” (Basamak şeklinde azalan)}

Antrenman hacminde tam ve keskin bir azalmanın olduğu "taper" çeşididir. İlk gün antrenman hacminde \%50 düşüş sağlanıp "taper" süresince bu hacim korunmalıdır.

“Taper" süresi: 1 - 3 hafta

Performans gelişimi: \% 1 - 1,5 iyileşme

Hacim azalımı: \% 65 - 70 şeklinde uygulanmaktadır.

\section{Linear "Taper" (Doğrusal azalan)}

Antrenman hacminde dereceli ve doğrusal azalmanın olduğu "taper" çeşididir. Örneğin; her çalışmada başlangıçtaki yükün \%5'i kadar azaltma yapılmalı ve aynı oranda buna devam edilmelidir.

Nonlinear "Taper": (Doğrusal olmayan azalma) Antrenman hacminde doğrusal olmayan azalmanın olduğu "taper" çeşididir. Son antrenman hacmine bağlı olarak doğrusal olmayan şekilde antrenman hacminde azaltma yapılarak uygulanmalıdır. Bu "taper" çeşidi, yavaş eksponansiyel ve hizlı eksponansiyel azalan olarak iki farklı şekilde uygulanmaktadır $(10,24-28)$ (Tablo 1 ).

Tablo 1. Yavaş ve hızlı eksponansiyel (üstel) azalan "taper" uygulaması parametreleri

\begin{tabular}{lll}
\hline & $\begin{array}{l}\text { Yavaş Üstel Azalan } \\
\text { "Taper" }\end{array}$ & $\begin{array}{l}\text { Hızlı Üstel Azalan } \\
\text { “Taper" }\end{array}$ \\
\hline Süre & Genellikle 4 - 8 gün & Genellikle 4 - 8 gün \\
Performans artışı & $\% 4$ & $\% 8$ \\
Hacim azalışı & $\% 60-90$ & $\% 60-90$ \\
\hline
\end{tabular}

Bu konudaki diğer benzer çalıșmalarda ise "taper" antrenmanları aşağıdaki şekilde sinıflanmaktadır;

\section{Minör (küçük) “Taper”}

Bu "taper" çeșidi sezon içinde optimal performansı elde etmek için bir hafta yada daha az süreyle yapılır. Kulüp sporcularının performans- larının test edilmesinde ve hazırlık maçları öncesinde kullanılmaktadır (29-31).

\section{Modarate (orta) "Taper”}

Takım sporlarında uygulanan bu "taper" çeşidi yıl içine yayılarak yapılmalıdır. Bu uygulamanın majör "taper"'a bașlamadan 4-6 hafta önce bitirilmesi gerekmektedir (29-31) (Tablo 2).

Tablo 2. Modarate (orta) "taper" antrenmanı parametreleri

\begin{tabular}{ll}
\hline Süre: & 2-3 Gün \\
\hline Volüm: & $\% 40-60$ azaltılır \\
Şiddet: & MaxV02'nin \%85 ve üstünde \\
Frekans: & Değişmez \\
\hline
\end{tabular}


Tablo 3. Majör (büyük) "taper" antrenmanı parametreleri

\begin{tabular}{ll}
\hline Süre: & 7-14 gün \\
\hline Volüm: & $\% 40-60$ azaltılır \\
Şiddet: & MaxV02' nin \%85 ve üstünde \\
Frekans: & $\% 20-50$ azaltılır \\
\hline
\end{tabular}

\section{Majör (büyük) “Taper”}

Yılın en önemli müsabakasından/yarışmasından önce, yılda bir kez ve 2-4 hafta olacak şekilde uygulanmalıdır (29-31) (Tablo 3).

\section{Antrenman Yükünün Bileșenleri}

Antrenman yükü, gerçekleştirilen toplam fiziksel antrenman performansıdır ve antrenman hacmi, yoğunluğu ve sıklığının birleşimidir $(32,33)$.

Antrenman yükünün bileşenleri 4 başlık altında incelenmektedir. Bunlar; antrenmanın şiddeti, antrenmanın süresi, antrenmanın sıklığı ve antrenmanın kapsamıdır (hacim).

“Taper” uygulamaları, günlük antrenmanın fizyolojik ve psikolojik stresini azaltmak ve antrenmanın frekans, yoğunluk ve hacminde yapılacak değişiklikler ile spor performansını optimize etmek için tasarlanmıştır $(16,23,32,34,35)$. "Taper" döneminde uygulanan antrenmanın hacim, süre ve şiddetine bağlı olarak bazı fizyolojik adaptasyonlar oluşmaktadır $(1,13,19)$.

\section{“Taper” Antrenmanlarının Süresi}

Bir antrenman birimlik programdaki yükleme evresi, bir yüklenmenin veya birçok yüklenmenin organizmadaki etki süresi olarak tanımlanmaktadır $(32,33)$. Literatürde, "taper" süresi ile sporcuların performans gelișimleri arasında anlamlı ilişkiler tespit edilmiştir (10, $14,23,24,36)$. "Taper" süresinin uygulama öncesi antrenmanların hacmi ve şiddetine bağlı olmakla birlikte 7-21 gün arasında olması uygun görünmektedir $(18,21,27,37)$. Milli yüzücülerde "taper" uygulamaları ile en yüksek performans değerlerinin 7 gün içinde alındığı belirtilmiştir (38).
Dayanıklılık sporcularında 21 günden fazla süren "taper" uygulamasinın performansı artırmaktan çok korumaya dönük olduğu tespit edilmiştir (27). Bununla ilgili pek çok matematiksel model ortaya konulmaya çalışılmış olsa da en uygun sürenin 2 hafta olduğu belirtilmektedir. Düşük kondisyonlu sporcular için hızlı "taper" uygulaması (6-10 gün) önerilmemekte, "taper" süresi sporcunun antrenmana olan adaptasyonu dikkate alınarak bireysel olarak belirlenmesi gerektiği ifade edilmektedir $(4,7,10,14,24,26,27,36,39)$. "Taper" süresince uyaranların büyük oranda azalması sebebiyle sporcuların performanslarında bazı düşüşler olacağı belirtilmektedir. Üst düzey sporcularda antrenman bırakıldıktan 1-4 hafta içinde sporcuların bazı özelliklerini kaybetmeye başladıkları görülmüştür $(24,36)$. Elit bisikletçilere 7-21 gün ve 21-28 gün sürelerle yapılan "taper" uygulamalarında sporcuların performanslarında gelişme görülürken, 42 gün süreyle yapılan "taper" antrenmanlarının performansı düşürdüğü saptanmıştır (24). Başka bir çalışmada elit bisikletçilere 21 gün boyunca antrenman şiddeti ve hacminin azaltıldığı submaksimal ve maksimal egzersiz sirasinda "taper" uygulamaları yapılmış, sporcuların bu dönemde fiziksel performanslarını korudukları tespit edilmiştir (40). Bir meta-analiz çalışmasında, antrenman sıklığ ve şiddetinin değişmediği, yükün \%41-60 azaltıldığı 2 haftalık "taper" uygulamasının sporcuların performansını önemli ölçüde artırdığı belirtilmiştir (24). Başka bir çalışmada kuvvet antrenmanı yapan sporcularda 16 haftalık bir direnç antrenmanı sonrasında 4 haftalık bir "taper" uygulamasının üst ve alt ekstremite maksimal kuvvet ve güç değerlerinde önemli artışlar sağladığı belirlenmiştir (41). 


\section{“Taper” Antrenmanlarında Hacim}

Antrenman hacmi, antrenmanda yapılan işin toplam miktarı olarak ifade edilmektedir $(32,33)$. "Taper" antrenmanlarının en belirgin özelliği antrenmanın hacminin azaltılmasıdır. "Taper" döneminde performanstaki artışla hacimdeki azalma arasında ters bir ilişki olduğu belirtilmektedir. Eğer antrenman hacmi yeteri kadar azaltılmaz ise sporcuların performanslarındaki gelişimin yeterli olmayacağı ifade edilmektedir $\quad(12,18,26,27,32,37,42-46,48,49)$. Antrenman hacminde yapılacak azaltmalar "taper" dönemi öncesi yapılan antrenmanlara bağlı olarak değișmektedir $(22,24)$. Fakat bu azaltmaların sporcuda detraining etkisi göstermemesi için dikkatli olmak gerekir. "Taper" döneminde antrenman hacmindeki azalmanın doğru planlanmasıyla sporcularda "detraining" etkisi görülmeyecektir (11). Mujika ve ark. tarafından yapılan bir çalışmada, orta mesafe koşucularında 6 günlük "taper" uygulamasında antrenman hacmi $\% 50$ ve $\% 75$ oranında azaltılmış, \%75'lik azaltmanın sporcuların performansında daha fazla artış gösterdiği rapor edilmiştir (43). Yüzücüler ile yapılan çalışmalarda, haftalık antrenman hacminin \%60-90 oranında azaltılması durumunda performanslarının arttığı görülürken $(18,49)$, mesafe koşucularında 7 günlük düşük şiddetli "taper" uygulamalarında antrenman hacminin \%62 azalmasının sporcuların performanslarında değişim yaratmadığı (50), yüksek şiddetli "taper" uygulamalarında \%85'lik azaltmanın ise sporcuların 5 kilometrelik koşu derecesini \%3 oranında geliștirdiği belirlenmiștir (43). Antrenman hacminin $\% 90$ ve $\% 85$ oranında azaltıldığı, şiddet ve sıklığın sabit kaldığı 6 günlük "taper" uygulamalarının sporcuların orta ve uzun mesafe koşu derece ve tükenme zamanlarını geliștirdiği tespit edilmiştir (43). Ayrica profesyonel futbolcular üzerinde yapılan bir başka çalışmada, antrenman şiddetinin değişmediği fakat antrenman süresi ve sıklığında azalmanın olduğu "taper" uygulaması ile sporcuların oyun sırasında yaptıkları șiddetli ve yüksek şiddetli koşularla sprint sayılarında önemli artışlar olduğu rapor edilmiştir (51). Bisiklet sporcuları üzerinde yapılan bir çalışmada 4 günlük "taper" uygulamasiyla sporcuların kas glikojen konsantrasyonlarında 17\%, 8 günlük "taper" uygulamasıyla ise 25\%'lik bir artış tespit edilmiştir (52). Bisiklet sporcuları üzerinde yapılan bir başka çalışmada, haftalık antrenman hacminin \%50 azaltıldığı 7 günlük "taper" uygulamasında sporcuların V02maks değerlerinin \%6 oranında arttığı saptanmıştır (34). Bir diğer çalışmada yoğun antrenmanlardan sonra yapılan "taper" uygulamasinın sporcuların V02maks değerlerinin gelişmesinde oldukça etkili olduğu belirtilmiştir (53).

Erkek futbolcularda 2 hafta devam eden "taper" uygulamasından sonra sporcuların kortizol, testosteron değerleriyle testosteron/kortizol oranına bakılmış, testosteron değeriyle testosteron/kortizol oranında belirgin artış, kortizol değerinde ise düşüş rapor edilmiştir (54).

"Taper" uygulamalarının sporcuların tamponlama kapasiteleri, oksidatif enzim aktiviteleri, kan hacmi ve kırmızı kan hücresi sayıları, kan laktatı, hemoglobin ve kas glikojen değerleriyle koşu ekonomilerinde iyileşme sağladığı belirtilmiştir. (12,38,39,44,47,50,52,55-57).

\section{“Taper" Antrenmanlarında Sıklık}

Antrenman sıklığl; yüklenme ile dinlenme arasındaki zamansal ilişki olarak tanımlanmaktadır $(32,33)$. "Taper" döneminde antrenman sıklığında değişiklik yapmaktan kaçınmalıdır. Antrenman hacmindeki azalmayla birlikte antrenman frekansında düşüş yapılmamalıdır. Çalışmaklar antrenman slklığından çok antrenman hacminin azaltılmasının daha etkili olduğunu göstermektedir $(24,48,58)$. Bir çalışmada antrenman sıklığının \%50-85 azaltıldı̆̆ı "taper" uygulamasında yüzücülerin performanslarında düşüş olduğu rapor edilmiştir (16). Oysa antrenman hacminin \%20-50 azaltılmasıyla yapılan 7 günlük "taper" uygulamalarında, sporcu performanslarında önemli artışlar olduğu rapor edilmektedir $(6,7,10,29,42)$. Yüzücülerde 5 haftalık "taper" uygulamasinda antrenmanın sıklık ve hacminde yapılan değişikliklerin etkilerine bakılmış, antrenman sıklığının sabit kaldığı, antrenman hacminin azaltıldığ (günde 3 saatten 1 saate) grupta 6 günlük uygulamanın \%12-15 arasında performans gelişimi sağladığı, antren- 
man sıklığının 6 günden 2 güne indirildiği, günlük antrenman hacminin değișmediği grupta ise performans düşüşü olduğu rapor edilmiştir (59). Mujika ve ark. tarafından orta mesafe koşucuları üzerinde yapılan çalışmada, 6 günlük "taper" uygulaması sonucunda 800 m koşu derecelerinde gelişim gözlenirken, 3 ve 6 . günlerde tam dinlenme uygulanan "taper" ile koşu derecelerinde gelişim olmadığı tespit edilmiştir (43).

\section{“Taper” Antrenmanlarının Şiddeti}

Antrenmanın şiddeti; birim zamanda yapılan iș ya da enerji çıktısı olarak tanımlanmaktadır $(32,33)$. "Taper" uygulamlarında antrenman hacminin düşmesi, şiddetinin ise artması gerektiği rapor edilmiştir $(11,12,24,26,42,58)$. \%70 V02maks şiddeti ile yapılan "taper" uygulamalarında performansta azalma, \%90 V02maks ve üzerindeki şiddette yapılan "taper" uygulamalarında ise performans artışı saptandığını gösteren çalışmalar bulunmaktadır $(10,24,29,42,60)$. Hicson ve ark. tarafından yapılan bir çalıșmada, antrenman hacmi ve sıklığının aynı kalmasına karşın, antrenman şiddetinde yapılan $1 / 3$ ya da $2 / 3^{\prime}$ lük bir azaltmanın performansta düşüşe neden olduğu; antrenman şiddetinin $1 / 3$ oranında azaltıldığ grubun performanslarında $\% 21,2 / 3$ oranında azaltıldığı grubun performanslarında ise \%30 düşüş saptandığı belirtilmiştir (61). Wittig ve ark. tarafından yapılan çalışmada, erkek mesafe koşucularında "taper" döneminde antrenman şiddetinin \%70'den fazla azaltılmasının koşu performansını \%1 oranında düşürdüğü, egzersiz şiddetinin "taper" döneminde korunması gerektiği rapor edilmiştir (45). Antrene bireylerde, antrenman şiddetinin antrenmana adaptasyonun korunması için önemli bir bileşen olduğu dile getirilmektedir (61). "Taper" döneminde optimal performans elde etmede egzersiz şiddetinin anahtar rol oynadığı belirtilmektedir $(16,26,27,48,49)$.
"Taper" uygulamalarını konu alan yayınlar incelendiğinde, çalışmaların daha çok bireysel ve dayanıklılık sporlarında (koşu, yüzme, bisiklet, kürek ve triatlon) yapıldığı görülmüştür. Buna karşılık, takım sporlarının fizyolojik talepleri, antrenman ve performansa ait çok yönlü yapıları nedeniyle bunlarla ilgili çok az çalışma bulunmaktadır (37). "Taper" antrenmanlarının süresiyle ilişkili olarak V02maks değerlerinin bazı çalışmalarda arttığı, bazılarında herhangi bir değişiklik olmadığı rapor edilmiştir (39). Yüzme sporcularında yapılan bir çalışmada sporcuların 21 gün devam eden bir "taper" uygulamasıyla VO2maks değerlerinin değişmediğ belirtilmiştir (62). Bazı çalışmalarda, sporcuların V02maks değerlerinde iyileşme olmamasına rağmen yapılan "taper" uygulamasıyla performanslarında gelişme olduğu belirtilmektedir $(27,63)$.

Tablo 4'de, "taper" antrenmanlarının V02maks üzerindeki etkilerinin araştırıldığı bazı çalışmalar yer almaktadır.

Yapılan birçok çalışmada "taper" uygulamalarının dinlenim kalp atım sayıları farklılık göstermezken, maksimal kalp atım sayılarında artış olduğu görülmüştür (39,63-67) (Tablo 5).

"Taper" antrenmanları sonrası maksimal egzersizlerde kan laktat seviyesinde artışlar olduğu, bu artışların kas glikojen depolarındaki artışla ilişkili olabileceği rapor edilmiştir $(19,45,47,50,52,56,57,63,64) . \quad 4$ hafta devam eden bir step "taper" uygulamasindan sonra koşucularda \%95 V02maks şiddetinde yapılan antrenmanlarda sporcuların kan laktat düzeylerinin yüksek olduğu belirlenmiștir (66). Elit kürekçilerde yapılan bir çalışmada ise, bir haftalık "taper" uygulamasının sonunda, sporcuların maksimal kan laktat değerlerinin 14.4'ten 15.8 mmol/L'ye çıktığı tespit edilmiştir (46). 
Tablo 4. "Taper” antrenmanlarının sporcuların $\mathrm{V}_{2 \text { maks }}$ değerleri üzerindeki etkileri

\begin{tabular}{|c|c|c|c|c|c|}
\hline Çalışma & Branşlar & $\begin{array}{l}\text { "Taper" } \\
\text { Süresi } \\
\text { (gün) }\end{array}$ & $\mathrm{VO}_{2 \mathrm{maks}}$ & $\begin{array}{l}\text { Performans } \\
\text { Testi }\end{array}$ & $\begin{array}{l}\text { Performans } \\
\text { Durumu \% }\end{array}$ \\
\hline $\begin{array}{l}\text { Jeukendrup et al. } \\
\text { (1992) }\end{array}$ & Bisiklet & 14 & + & $8,5 \mathrm{~km}$ & 7,2 \\
\hline Rietjens et al. (2001) & Bisiklet & 21 & $=$ & $\mathrm{MaxV0}_{2}$ testi & $=$ \\
\hline $\begin{array}{l}\text { Dressendorfer et al. } \\
(2002)\end{array}$ & Bisiklet & 10 & + & $20 \mathrm{~km}$. & 1,2 \\
\hline Neary et al.(2003) & Bisiklet & 7 & + & $20 \mathrm{~km}$. & 5,4 \\
\hline Neary et al.(2003) & Bisiklet & 7 & + & $40 \mathrm{~km}$ & $2,2-4,3$ \\
\hline $\begin{array}{l}\text { Van handel et al. } \\
\text { (1998) }\end{array}$ & Bisiklet & 20 & + & Raporlamamış & \\
\hline $\begin{array}{l}\text { D'Acquisto } \\
\text { al.(1992) }\end{array}$ & Bisiklet & $14+28$ & $=$ & $100 m-400 m$ & $4-8$ \\
\hline Hug et al. (2014) & Maraton & 21 & + & $\begin{array}{l}\text { Submaksimal } \\
\text { Koşu Testi } \\
(10 \mathrm{dk})\end{array}$ & $4-8$ \\
\hline $\begin{array}{l}\text { Skovgaard et al. } \\
(2016)\end{array}$ & Atletizm & 14 & + & Raporlamamış & 2.7 \\
\hline
\end{tabular}

(+) artış var, (-) azalış var, (=) değişim yok

Yukarıdaki tablo, Mujika ve ark.'nın (36) “Physiological Changes Associated with the Pre-Event Taper in Athletes" başlıklı çalışmalarından izin alınarak kullanılmıştır.

Tablo 5. "Taper" antrenmanlarının sporcuların dinlenim ve maksimal kalp atım üzerindeki etkileri

\begin{tabular}{|c|c|c|c|c|c|c|}
\hline \multirow[b]{2}{*}{ Çalışma } & \multirow{2}{*}{ Branşlar } & \multirow{2}{*}{$\begin{array}{l}\text { “Taper” } \\
\text { Süresi } \\
\text { (gün) }\end{array}$} & \multirow{2}{*}{$\begin{array}{l}\text { Dinlenim } \\
\text { Kalp Atım } \\
\text { Sayısı }\end{array}$} & & \multirow{2}{*}{$\begin{array}{l}\text { Performans } \\
\text { Testi }\end{array}$} & \multirow{2}{*}{$\begin{array}{l}\text { Performans } \\
\text { Durumu \% }\end{array}$} \\
\hline & & & & $\begin{array}{l}\text { Kalp Atım } \\
\text { Sayısı }\end{array}$ & & \\
\hline $\begin{array}{l}\text { Jeukendrup et } \\
\text { al. (1992) }\end{array}$ & Bisiklet & 14 & - & + & $8.5 \mathrm{~km}$ & 7,2 \\
\hline $\begin{array}{l}\text { McConell et al. } \\
\text { (1993) }\end{array}$ & Atlet & 28 & $=$ & + & $5 \mathrm{~km}$ & $-1,2$ \\
\hline $\begin{array}{l}\text { D'Acquisto et } \\
\text { al. (1992) }\end{array}$ & Yüzme & $14-28$ & $=$ & + & $\begin{array}{l}100 \quad \mathrm{~m}- \\
400 \mathrm{~m}\end{array}$ & $4-8$ \\
\hline
\end{tabular}

(+) artış var, (-) azalış var, (=) değişim yok

Yukarıdaki tablo, Mujika ve ark.'nın (36) "Physiological Changes Associated with the Pre-Event Taper in Athletes" başlıklı çalışmalarından izin alınarak kullanılmıştır. 
7 gün devam bir "taper" sonrasında yüzme sporcuların kas güçlerinin önemli ölçüde azaldığı ve submaksimal kan laktat seviyelerinin ise 28 gün sonunda arttığı bulunmuştur (60). Bunun yanında, 14 gün devam eden "taper" son- rasında ise sporcuların egzersiz sonrası kan laktat, $\mathrm{pH}$ ve bikarbonat değerleri ve kalp atım hızlarında önemli değişiklikler olmadığı rapor edilmiştir (49) (Tablo 6).

Tablo 6. "Taper" antrenmanlarının sporcuların laktik asit değerleri üzerindeki etkileri

\begin{tabular}{|c|c|c|c|c|c|}
\hline Çalışma & Branşlar & $\begin{array}{l}\text { “Taper" } \\
\text { Süresi (gün) }\end{array}$ & $\begin{array}{l}\text { Laktik } \\
\text { Asit } \\
\text { (mmol/L) }\end{array}$ & $\begin{array}{l}\text { Performans } \\
\text { Testi }\end{array}$ & $\begin{array}{l}\text { Performans } \\
\text { Durumu \% }\end{array}$ \\
\hline $\begin{array}{l}\text { Bonifazi et al. } \\
(2000)\end{array}$ & Yüzme & $14-21$ & + & $400 \mathrm{~m}$ & $1,5-2,1$ \\
\hline $\begin{array}{l}\text { Mujika et al. } \\
(2000)\end{array}$ & Atletizm & 6 & + & $800 \mathrm{~m}$ & $=$ \\
\hline Smith (2000) & Yüzme & 7 & $=$ & $500 \mathrm{~m}$ & $=$ \\
\hline $\begin{array}{l}\text { Steinacker et al. } \\
(2000)\end{array}$ & Kürek & 7 & + & $2000 \mathrm{~m}$ & 6,3 \\
\hline $\begin{array}{l}\text { Mujika et al. } \\
(2002)\end{array}$ & Atletizm & 6 & + & $800 \mathrm{~m}$ & $0,4-1,9$ \\
\hline
\end{tabular}

(+) artış var, (-) azalış var, (=) değișim yok

Yukarıdaki tablo, Mujika ve ark.'nın (36) "Physiological Changes Associated with the Pre-Event Taper in Athletes" başlıklı çalışmalarından izin alınarak kullanılmıştır.

\section{Sonuç ve Öneriler}

"Taper" uygulamalarının sporcuların performans gelişimine katkıda bulunduğu görülmüştür. "Taper" döneminde optimal performans elde etmek için aşağıdaki faktörler dikkate alınmalıdır. "Taper" uygulamalarında:

1. Antrenman şiddeti korunmalı ya da hafif arttırılmalıdır.

2. Antrenman hacmi $\% 60-90$ oranında azaltılmalıdır.

3. Antrenman sıklı̆̆ı azaltılmamalı veya en fazla $\% 20$ azaltılmalıdır.

4. "Taper" süresi bireysel olarak değişebilmekle birlikte, 7-21 gün arasında olmalıdır.

5. Doğrusal olmayan, hızlı eksponansiyel azalan "taper" uygulaması, sporcuların performans gelişimlerinde daha hızlı etki göstermektedir.

\section{KAYNAKLAR}

1. Bishop D, Edge J. The effects of a 10-day taper on repeated-sprint performance in females. J Sci Med Sport. 2005; 8:2:200-209.

2. Aubry A, Hausswirth C, Louis J, et al. Functional overreaching: the key to peak performance during the taper? Med Sci Sports Exerc. 2014; 46: 1769-1777.

3. Baioumy ME, Ghazy AM. Effects of a Major Taper Training Program on some Physical Variables and Specific Fitness for Judokas. Int Sci J Phy Edu Sport Sci. 2015;2(2):1-10.

4. Spilsbury KL, Fudge BW, Ingham SA, et al. Tapering Strategies in elite British Endurance Runners. Eur J Sport Sci. 2014; 15: 1-7.

5. Freitas CG, Aoki MS, Franciscon CA, et al. Psychophysiological responses to overloading and tapering phases in elite young soccer players. Pediatr Exerc Sci. 2014; 26(2):195-202.

6. Gerald SZ. Evidence and possible mechanisms of altered maximum heart rate with endurance training and tapering. Sport Med. 2000; 29(1): 13-26.

7. Hellard P, Avalos M, Hausswirth C, et al. Identifying optimal overload and taper in elite swimmers over time. J Sports Sci Med. 2013; 12: 668-678. 
8. Zaras N, Stasinaki A, Krase A, et al. Effects of tapering with light vs. heavy loads on track and field throwing performance. J Strength Cond Res. 2014; 28: 34843495.

9. Farhangimaleki N, Zehsaz F, Tiidus PM. The effect of tapering period on plasma pro-inflammatory cytokine levels and performance in elite male cyclists. J Sports Sci Med. 2009; 8(4): 600-606.

10.Mujika I, Padilla S. Scientific bases for precompetition tapering strategies. Med Sci Sports Exerc. 2003; 35(7): 1182-1187.

11.Mujika I. Intense training: The key to optimal performance before and during the taper. Scand J Med Sci Sports. 2010; 20 (Suppl. 2): 24-31.

12.Murach KA, Bagley JR. Less is more: The physiological basis for tapering in endurance, strength, and power athletes. Sports 2015; 3(3): 209-218.

13.Trinity JD, Pahnke MD, Reese EC, et al. Maximal mechanical power during a taper in elite swimmers. Med Sci Sports Exerc. 2006; 38, (9): 1643-9.

14.Thomas L, Mujika I, Busso T. Computer simulations assessing the potential performance benefit of a final increase in training during pre-event taper. J Strength and Cond Res. 2009; 23(6): 1729-1736.

15.Pritchard H, Keogh J, Barnes M, et al. Effects and mechanisms of tapering in maximizing muscular strength. Strength Cond J. 2015;37(2):72-83.

16.Costill D, King D, Thomas R, et al. Effects of reduced training on muscular power in swimmers. Phys Sports Med. 1985;13(2): 94-101.

17.Noakes T. Lore of Running. 4th ed. Champaign, IL: Human Kinetics, 2001.

18.Ghazy AM, Baioumy ME, Hamouda MA. Effects of Taper on Elite Collegiate Female Judokas, J. Appl Sports Sci. 2016; 6(4): 42-49.

19.Coutts A, Reaburn P, Piva TJ, et al. Changes in selected biochemical, muscular strength, power, and endurance measures during deliberate overreaching and tapering in rugby league players. Int J Sports Med. 2007; 28: 116-124.

20.Slattery KM, Wallace LK, Bentley DJ, et al. Effect of training load on simulated team sport match performance. Appl Physiol Nutr Metab. 2012; 37(2):315-22.

21.Thomas L, Busso T. A theoretical study of taper characteristics to optimize performance. Med Sci Sports Exerc. 2005; 37(9):1615-21.

22.Thomas L, Mujika I, Busso T. A model study of optimal training reduction during pre-event taper in elite swimmers. J Sports Sci. 2008; 26:643-52.

23.Nikbakht H, Keshavarz S, Ebrahim K. The Effects of Tapering on Repeated Sprint Ability (RSA) and Maximal Aerobic Power in Male Soccer Players. American J Sci Res. 2011; 30:125-133.
24.Bosquet E, Montpetetıt J, Arvisais D, et al. Effect of tapering on performance: a meta-analysis. Med Sci Sports Exerc. 2007; 39(8): 1358-65.

25.Banister EW, Carter JB, Zarkadas PC. Training theory and taper: validation in triathlon athletes. Eur J Appl Physiol Occup Physiol. 1999; 79(2): 182-91.

26.Wilson JM, Wilson GJ. A practical approach to the taper. Strength Cond J. 2008;30 (2):10-17.

27.Houmard JA, Johns RA. Effects of taper on swim performance: practical implications. Sports Med. 1994; 17:224-32.

28.Krespi M, Sporis G, Jelaska PM. Effects of two different tapering protocols on fitness and body composition in young soccer players: positional differences. Acta Kinesiologica. 2018; 1:62-71.

29. Hooper SL, Mackinnon LT, Howard A. Physiological and psychometric variables for monitoring recovery during tapering for major competition. Med Sci Sports Exerc. 1999; 31(8): 1205-10.

30.Hellard P, Scordia C, Avalos M et al. Modelling of optimal training load patterns during the 11 weeks preceding major competion in elite swimmers. Appl Physiol Nutr Metab. 2017; 42(10):1106-1117

31.Baioumy ME, Ghazy AM. Effects of a Major Taper Training Program on some Physical Variables and Specific Fitness for Judokas. Int Scientific J Phy Edu Sport Sci. 2015; 2(2):31-40.

32.Le Meur Y, Hausswirth C, Mujika I. Tapering for competition: A review. Sci Sports. 2012; 27(1): 77-87.

33.Brannström A, Rova A, Guo Yu J. Effects and Mechanisms of Tapering in Maximizing Muscular Power, Sport and Art. 2013; 1(1): 18-23.

34.Neary JP, Martin TP, Quinney HA. Effects of taper on endurance cycling capacity and single muscle fiber properties. Med Sci Sports Exe. 2003; 35(11): 18751881.

35.Pyne DB, Mujika I, Reilly T. Peaking for optimal performance: Research limitations and future directions. J Sports Sci. 2009; 27: 195-202.

36.Mujika I, Padilla S, Pyene D, et al. Physiological changes associated with the pre-event taper in athletes. Sports Med. 2004; 34(13): 891-927.

37.Johns RA, Houmard JA, Kobe RW, et al. Effects of taper on swim power, stroke distance and performance. Med Sci Sports Exerc. 1992; 24(10); 1141-1146.

38.Yamamoto Y, Mutoh Y, Miyashita M. Hematological and biochemical indices during the tapering period of competitive swimmers. Swimming Science V, Int Series Sport Sci. 1988; (18): 243-249.

39.Mujika I. Tapering for triathlon. J Human Sport Exerc. 2011; 6:264-270.

40.Rietjens GM, Keizer HA, Kuipers $\mathrm{H}$, et al. A reduction in training volume and intensity for 21 days does not impair performance in cyclists. Br J Sports Med. 2001; 35:431-434. 
41.Izquierdo M, Ibanez J, Gonzalez-Badillo JJ, et al. Detraining and tapering effects on hormonal responses and strength performance. J Strength Cond Res. 2007; 21(3): 768-775.

42.Spilsbury KL, Tapering strategies for elite endurance running performance. A Doctoral Thesis. 2016, Submitted in Loughborough University.

43.Mujika I, Goya A, Ruiz E, et al. Physiological and performance responses to a 6-day taper in middledistance runners: influance of training frequency. Int J Sports Med. 2002; 23(5): 367- 373.

44.Houmard JA. Impact of reduced training on performance in endurance athletes. Sports Med. 1991; 12(6): 380-93.

45.Wittig AF, McConell GK, Costill DL, et al. Psychological effects during reduced training volume and intensity in distance runners. Int. J. Sports Med. 1992; 13 (6): 497-499.

46.Mcneely E, Samdeler D. Tapering for endurance athletes. Strength Cond J. 2007; 29:18-24.

47.Toubekis AG, Drosou E, Gourgoulis V. et al. Competitive Performance, Training Load and Physiological Responses During Tapering in Young Swimmers. J Hum Kinet. 2013;(38):125-134.

48.De Lacey J, McGuigan M, Hansen K, et al. The Effects of Tapering on Power-Force-Velocity Profiling and Jump Performance in Professional Rugby League Players. $J$ Strength Cond Res. 2014; (28):3597.

49.Costill DL, Thomas R, Robergs A, et al. Adaptations to swimming training: influence of training volume. Med Sci Sports Exerc. 1991; (23): 371-7.

50.Shepley B, MacDougall JD, Cipriano N, et al. Physiological effects of tapering in highly trained athletes. J Appl Physiol. 1992; 72(2): 706-11.

51.Fessi MS, Zarrouk N, Di Salvo W, et al. Effects of tapering on physical match activities in professional soccer players. J Sports Sci. 2016; 34(24): 2189-2194.

52.Neary JP, Martin TP, Reid DC, et al. The effects of a reduced exercise duration taper programme on performance and muscle enzymes of endurance cyclists. Eur J Appl Physiol. 1992; 65: 30-6.

53.Fortes LS, Vianna JM, Silva DMS, et al. Effects of tapering on maximum aerobic power in indoor soccer players. Rev Bras Cineantropom Desempenho Hum. 2016; 18(3): 341-352.

54.Dehkordi KJ, Ebrahim K, Gaeini A, et al. The effect of two types of tapering on cortisol, testosterone and testosterone/cortisol ratio in male soccer players. Int J Basic Sci Appl Res. 2014; 3(2): 79-84.
55.Grivas GV, The effects of tapering on performance in elite endurance runners: A systematic review. Int $J$ Sports Sci. 2018; 8(1): 8-13.

56.Papoti M, Martins LE, Cunha SA, et al. Effects of taper on swimming force and swimmer performance after an experimental ten-week training program. J Strength Cond Res. 2007; (21): 538-542.

57.McConell GK, Costill DL, Widrick JJ, et al. Reduced training volume and intensity maintain aerobic capacity but not performance in distance runners. Int J Sports Med. 1993; 14: 33-7.

58.Chtourou H, Chaouachi A, Driss T, et al. The effect of training at the same time of day and tapering period on the dirunal variation of short exercise performances. J Strength Cond Res. 2012; 26(3): 697708.

59.Mujika I, Busso T, Lacoste L, et al. Modeled responses to training and taper in competitive swimmers. Med Sci Sports Exerc. 1996; 28(2): 251-8.

60.Vollaard NB, Cooper CE, Shearman JP. Exerciseinduced oxidative stress in overload training and tapering. Med Sci Sports Exerc. 2006; 38(7): 1335-41.

61.Hickson RC, Foster C, Pollock ML, et al. Reduced training intensities and loss of aerobic power, endurance, and cardiac growth. J Appl Physiol. 1985; (58): 492-499.

62.Van Handel PJ, Katz A, Troup JP, et al. Oxygen consumption and blood lactic acid response to training and taper. Swimming Science V, Int Series Sport Sci. 1988; (18): 269-275.

63.Neufer PD, Costill DL, Fielding RA, et al. Effects of reduced training on muscular strength and endurance in competitive swimmers. Med Sci Sports Exerc. 1987; 19(5): 486-490.

64.Marrier B, Robineau J, Piscione J, et al. Supercompensation Kinetics of Physical Qualities during a Taper in Team Sport Athletes. Int J Sports Physiol Perf. 2017; 2(2): 32-39.

65. Haykowsky MJ, Smith DJ, Malley L, et al. Effects of short term altitude training and tapering on left ventricular morphology in elite swimmers. Can J Cardiol. 1998; 14: 678-81.

66.Flynn MG, Pizza FX, Boone Jr JB, et al. Indices of training stress during competitive running and swimming seasons. Int J Sports Med. 1994; 15: 21-6.

67.D'Acquisto LJ, Bone M, Takahashi S, et al. Changes in aerobic power and swimming economy as a result of reduced training volume. In: MacLaren $\mathrm{D}$, Reilly $\mathrm{T}$, Lees A, editors. Biomechanics and Medicine in Swimming: Swimming Science VI. London: E \& FN Spon, 1992: 201-5. 